\title{
Um modelo de referência para o processo de desenvolvimento de produtos de empresas do setor moageiro de trigo
}

\author{
Samanta Ullmann de Campos, ${ }^{\mathrm{a}, *}$, José Luis Duarte Ribeiro \\ a,*samantaeng99@yahoo.com.br, PPGEP/UFRGS, Brasil \\ bribeiro@producao.ufrgs.br, PPGEP/UFRGS, Brasil
}

\begin{abstract}
Resumo
Este artigo apresenta um modelo de referência para o processo de desenvolvimento de produtos (PDP) no setor moageiro de trigo. 0 modelo objetiva facilitar os projetos de novos produtos, avaliando necessidades, requisitos e limitações. Ele pode contribuir para a integração e comunicação entre as áreas funcionais, reduzindo o tempo de desenvolvimento. A estrutura operacional do modelo é composta por três macrofases e oito fases. No término de cada fase, as informações são compiladas em forma de um documento, que deve passar pela avaliação da direção (gate). A aplicação do modelo foi realizada a partir de um plano para sistematizar o PDP de uma empresa. A intervenção para ajustar o modelo à empresa contemplou: análise da situação atual do PDP, proposição de melhorias e aplicação do modelo. Entre os resultados, destaca-se a facilidade de enquadrar as soluções propostas para melhorar o PDP ao modelo referencial, mostrando a exequibilidade do mesmo.
\end{abstract}

Palavras-chave

Processo de desenvolvimento de produto. Setor moageiro de trigo. Modelo de referência.

\section{Introdução}

Por três décadas, toda a cadeia de trigo brasileira ficou regulada pelo governo, através do Decreto-lei n. ${ }^{\circ}$ 210. Logo após a desregulamentação, em 1990, o setor moageiro de trigo sofreu grandes transformações decorrentes da abertura comercial, aumento da concorrência e retração do consumo de farinha doméstica, ocasionado pelo momento econômico do país. A reestruturação do setor foi obtida com a concentração da economia e enxugamento da capacidade instalada. Até o momento, a moagem efetiva de trigo no Brasil ainda é menor que a capacidade instalada. Essa capacidade ociosa das empresas pode ser diminuída com a perspectiva de aumentar o consumo de farinha e produtos à base de farinha, uma vez que o Brasil possui baixo consumo de farinha, próximo a $50 \mathrm{~kg} / \mathrm{ano} / \mathrm{per}$ capita. Em outros países da América do Sul, por exemplo Chile, Argentina e Uruguai, esse consumo alcança $100 \mathrm{~kg} / \mathrm{ano} / \mathrm{per}$ capita.
Tendo em vista o aumento da concorrência, a mudança no poder aquisitivo da população brasileira e o desenvolvimento de novas tecnologias, é fundamental que as empresas do setor moageiro considerem o desenvolvimento de produtos como uma necessidade estratégica para melhorar a competitividade no mercado. Cabe ao PDP identificar e antecipar as necessidades do mercado, além de propor soluções por meio de projetos de produtos que atendam a tais necessidades (ROZENFELD et al., 2006). 0 desenvolvimento do produto pode ser definido como um processo que, através de um conjunto de atividades, transforma dados e informações sobre oportunidades e técnicas em bens e informações para fabricação de um produto. A maioria das oportunidades de desenvolvimento visa atender novos mercados, incorporar tecnologias diversas, adequar a empresa a novos padrões ou requisitos legais. É por meio desse processo que 
a empresa pode criar produtos mais competitivos, focados em um objetivo (ROZENFELD et al., 2006; CLARK; FUJIMOTO, 1991).

Diante dessa oportunidade, este artigo aborda o PDP discutido no âmbito do setor moageiro de trigo. 0 principal objetivo é a construção de um modelo de referência para o PDP no setor de interesse, baseado na abordagem de desenvolvimento integrado de produtos e passível de ser aplicado às características de cada empresa.

Este artigo está organizado conforme segue. A próxima seção, onde são apresentadas as práticas de gestão para o PDP, relata as abordagens de condução do desenvolvimento, os modelos de referência e o gerenciamento da informação. Em seguida, na seção 3 , é descrito o diagnóstico do ambiente moageiro de trigo, com o objetivo de conferir generalidades ao modelo do PDP proposto. $\mathrm{Na}$ quarta seção, é mostrado um modelo de referência do PDP para a indústria moageira de trigo. Na quinta seção é estudada a aplicação do modelo proposto em uma empresa situada no Rio Grande do Sul.

\section{Práticas de gestão no processo de desenvolvimento de produtos}

A excelência em desenvolvimento de produtos ocorre quando a empresa consegue organizar adequadamente estratégia, estrutura organizacional, sistematização das atividades, habilidades técnicas, abordagens para resolução de problemas e mecanismos de aprendizagem aliados à cultura dominante da empresa (ROZENFELD et al., 2006; PAULA, 2004).
Rozenfeld et al. (2006) expõem que a abordagem utilizada para conduzir o PDP é influenciada pela maturidade de gestão que a empresa se encontra. 0 modo de conduzir o PDP pode ocorrer sob diferentes visões. 0 autor classifica as abordagens utilizadas na condução do PDP conforme Quadro 1.

A gestão de desenvolvimento sequencial era muito empregada até o início da década de 1980, entretanto muitas empresas nacionais ainda adotam a estrutura organizacional funcional, pois valorizam a experiência da pessoa para executar a funções específicas. Outro fator que limita a evolução da gestão para a integração funcional é a necessidade de investimentos e priorização em comunicação e coordenação de atividades (MANO; TOLEDO, 2005). De acordo com Paula (2004), a abordagem sequencial costuma ser utilizada por empresas que apresentam processos muito técnicos, pois o número de funcionários com conhecimentos para desenvolver atividades específicas é reduzido.

Outra abordagem de desenvolvimento com característica sequencial é a metodologia de projetos, que visa a excelência funcional através da sistematização das atividades. Os métodos sistêmicos são utilizados para melhorar a eficiência das atividades, facilitando a obtenção de soluções, a avaliação e o detalhamento dos processos de fabricação (ROZENFELD et al., 2006).

No fim dos anos 1980, a engenharia simultânea (ES) surgiu, como um modelo capaz de integrar e organizar as atividades de engenharia. Essa abordagem ampliou a comunicação entre as diversas áreas, propondo a participação de clientes e fornecedores no PDP e, principalmente, mostrando as vantagens da realização de atividades simultâneas. A utilização de times funcionais faz

Quadro 1. Evolução da gestão de desenvolvimento de produtos, abordagem do PDP e suas principais características.

\begin{tabular}{|c|c|c|}
\hline $\begin{array}{l}\text { Evolução da } \\
\text { gestão de DP }\end{array}$ & $\begin{array}{l}\text { Abordagem } \\
\text { do PDP }\end{array}$ & Principais caracteristicas da abordagem \\
\hline \multirow{2}{*}{$\begin{array}{l}\text { Desenvolvimento } \\
\text { sequencial de } \\
\text { produtos }\end{array}$} & Sequencial & Divisão de tarefas, especialização, ênfase nas funções de cada área \\
\hline & Metodologia de projetos & Divisão de tarefas, especialização, áreas funcionais \\
\hline \multirow{3}{*}{$\begin{array}{l}\text { Desenvolvimento } \\
\text { integrado de } \\
\text { produtos }\end{array}$} & Engenharia simultânea & $\begin{array}{l}\text { Equipes multidisciplinares, utilização de técnicas e métodos, elaboração concomitante de } \\
\text { atividades }\end{array}$ \\
\hline & Stage gate & Foco no processo de negócio, implementação de avaliações na transição de fases \\
\hline & Modelo de funil & $\begin{array}{l}\text { Foco no processo do negócio, integração do desenvolvimento de produto com a estratégia } \\
\text { de mercado e tecnológica (gestão de portfólio) }\end{array}$ \\
\hline \multirow{4}{*}{$\begin{array}{c}\text { Novas } \\
\text { abordagens } \\
\text { para o } \\
\text { desenvolvimento } \\
\text { integrado de } \\
\text { produtos }\end{array}$} & Lean & $\begin{array}{l}\text { Trabalho em equipe, simplificação e padronização para diminuir esforço de atividades } \\
\text { rotineiras, ênfase nas atividades iniciais }\end{array}$ \\
\hline & Design for Six Sigma & Otimização das soluções de projeto utilizando principalmente ferramentas estatísticas \\
\hline & Modelos de maturidade & $\begin{array}{l}\text { Foco na melhoria do PDP por meio de níveis de maturidade. Uso de indicadores para avaliar } \\
\text { o grau de evolução do PDP }\end{array}$ \\
\hline & $\begin{array}{l}\text { Gerenciamento do ciclo } \\
\text { de vida dos produtos }\end{array}$ & $\begin{array}{l}\text { Integração de todas as etapas do ciclo de vida do produto, através das ferramentas } \\
\text { computacionais de integração e gerenciamento }\end{array}$ \\
\hline
\end{tabular}


com que as pessoas troquem experiências, o que aumenta a qualidade e a rapidez de execução das atividades de desenvolvimento. A integração entre as diversas áreas para resolver problemas (desenvolver produtos) resulta na conclusão dos projetos dentro do prazo, dentro dos limites de custo do produto, reduzindo as chances de retrabalho. Dessa forma, a integração funcional pode influenciar diretamente o desempenho do PDP (ROZENFELD et al., 2006; COOPER, 1994; CLARK; FUJIMOTO, 1991).

Dentre os preceitos originais da ES, destacam-se a minimização dos níveis hierárquicos na empresa, distribuição da informação simultaneamente, capacitação de funcionários e reconhecimento do conhecimento tácito do pessoal de nível operacional. A gestão da ES trata o desenvolvimento de produtos de uma maneira integrada e sistêmica, com a utilização de técnicas como CAD, QFD, matriz de pugh e outras (ROZENFELD et al., 2006; PINOTT, 2003).

Após a engenharia simultânea, surgiram outras abordagens do desenvolvimento integrado de produtos (DIP). A principal mudança foi estabelecer uma abordagem de negócio, priorizando o alinhamento estratégico da empresa e o PDP. A abordagem do funil de desenvolvimento, descrita por Clark e Wheelwright (1994), caracterizou o início do PDP sendo conduzido por meio de um processo de negócio (gestão de portfólio). 0 objetivo dessa abordagem é criar um portfólio de projetos bem avaliado, onde somente os produtos com maior probabilidade de sucesso seguem em desenvolvimento. No final do desenvolvimento, esses produtos chegam ao mercado estrategicamente bem posicionados e alinhados aos objetivos do negócio.

Outra abordagem do desenvolvimento integrado de produtos, muito utilizada nos modelos de referência atuais, é o Stage Gate. Segundo Cooper (1993), o sistema Stage Gate é uma proposta para conduzir o PDP ao sucesso através de avaliações em vários estágios de desenvolvimento. Após a conclusão de cada estágio há um gate que controla a qualidade do projeto. De acordo com o autor o número de estágio pode variar de 4 a 6 .

0 sucesso de um novo produto está relacionado com as atividades que compõem o PDP, como elas são executadas e como elas se encaixam no processo. Embora muitas empresas possuam um processo sistêmico de PDP, o sucesso de um novo produto pode não ocorrer, devido a deficiências na condução de alguma atividade crítica. Esses problemas podem causar poucos estragos se houver um processo de avaliação das principais atividades em gates (COOPER; KLEINSCHMIDT, 1986).
Segundo Rozenfeld et al. (2006), um dos desafios para a eficiência e a melhoria contínua do DP é a efetiva utilização das práticas consolidadas no DIP. Apesar de esses conceitos terem iniciado em 1980, ainda é raro encontrar empresas que possuam um PDP sistematizado que utilize de maneira disciplinada as práticas do DIP.

As novas abordagens para o desenvolvimento de produtos, de acordo com Rozenfeld et al. (2006), são: Lean, Design for Six Sigma, modelos de maturidade e gerenciamento do ciclo de vida dos produtos. Essas abordagens visam simplificar a formalização do PDP por meio de formas mais avançada de trabalho em equipe, utilizando ferramentas computacionais e técnicas estatísticas para buscar soluções inovadoras.

\subsection{Modelos de referência para o PDP}

Diversos autores propõem modelos de referência com abordagens de gestão, etapas/ fases do processo, controles e ferramentas necessárias para desenvolver um novo produto. 0 objetivo da modelagem é melhorar: (i) o posicionamento dos participantes dentro do PDP; (ii) o fluxo de informação; (iii) diminuir o tempo de desenvolvimento; (iv) reduzir custo; e (v) aumentar a chance de sucesso do novo produto.

0 modelo deve contemplar a forma de apresentação da estrutura operacional do PDP, para que todos os participantes compreendam o ciclo de desenvolvimento do produto. Cada autor atribui à sua estrutura diferentes nomenclaturas $\mathrm{e}$ níveis de detalhamento para as etapas do processo, que refletem as experiências de pesquisadores e de empresas pesquisadas. A apresentação da estrutura facilita a entrada de informações necessárias para cada fase, assim como permite a visualização dos documentos de saída de cada fase, que muitas vezes são utilizados como informações de entrada para a próxima fase, além de delimitarem o projeto (PAULA, 2004; PENSO, 2003; ROZENFELD et al., 2006; LAIDENS, 2007).

Segundo Rudder, Ainsworth e Holgate (2001), uma empresa não pode seguir um modelo de referência em particular. Ela deve abordar os fundamentos de um modelo de referência, avaliar a importância de cada etapa, adaptá-lo e alterá-lo para as situações particulares. A adaptação da estrutura operacional do PDP deve ser realizada para cada projeto. De acordo com Fuller (1994), o projeto de um novo produto alimentício pode ser classificado conforme o tipo de novidade que o produto apresenta no mercado. A classificação 
dos projetos auxilia as empresas a focarem melhor seus processos de desenvolvimento, uma vez que cada classificação possui características peculiares e níveis de inovação diferentes. 0 tipo de classificação define o grau de detalhamento necessário na estrutura. 0 Quadro 2 apresenta a classificação de novos produtos segundo Fuller (1994).

$\mathrm{Na}$ literatura, os modelos de Penso (2003), Paula (2004) e Rozenfeld et al. (2006) destacam-se devido ao detalhamento das fases e atividades. A gestão de desenvolvimento integrado de produtos na abordagem do Stage Gate de Cooper (1993) está presente nesses modelos. Os gates avaliam as atividades realizadas após uma fase e decidem o rumo do projeto.

A proposta de Penso (2003) direcionada à indústria alimentícia está baseada nas metodologias de projeto de produto e visa o emprego de ferramentas para apoiar as atividades do PDP. 0 modelo foi elaborado a partir de seis diretrizes que orientam o processo de proposição do modelo. As diretrizes são: (i) forma de apresentação do modelo, para indicar o início, meio e fim; (ii) desdobramento do PDP, para facilitar a visibilidade das atividades; (iii) entradas e saídas do PDP; (iv) ferramentas de apoio ao PDP, para auxiliar a execução de atividades; (v) sistema de avaliação dos resultados do PDP ao final de cada fase; e (vi) apresentação dos resultados do PDP sempre documentados. De acordo a avaliação realizada por Penso (2003), o modelo contribui para a sistematização do PDP, pois o uso de ferramentas de apoio e a formação de equipes multidisciplinares aprimoram o processo, minimizam o reprojeto e auxiliam na execução de atividades e tomada de decisões. A modelagem é estruturada em macrofases, fases e atividades, onde as fases são: planejamento estratégico, planejamento do portfólio de produtos, planejamento de produto, projeto informacional, projeto conceitual, projeto detalhado, preparação da produção, lançamento do produto, acompanhamento do produto, retirada do produto do mercado.
0 modelo apresentado por Paula (2004) foi desenvolvido para a indústria farmacêutica, enfatizando os passos para obtenção de registro do medicamento na Anvisa. 0 modelo contempla um departamento de assuntos regulatórios, que, segundo a autora, foi desenvolvido devido ao grande volume de estudos que formam o dossiê de registro de medicamentos, necessário para comercialização do produto. Este departamento é coordenado pela equipe do P\&D. A autora destaca que o modelo considera o acúmulo de funções por parte dos integrantes, devido ao setor possuir grande número de empresas de pequeno ou médio porte. Segundo a autora, o modelo possui algumas vantagens, tais como: (i) oferece uma visão comum do PDP, nivelando os conhecimentos dos participantes; (ii) permite a visão integrada do processo, destacando seus elementos, suas estratégias, atividades e informações, recursos e organização, assim como as suas inter-relações; e (iii) facilita o fluxo de informação dentro das organizações. A estrutura operacional do PDP é dividida em macroetapas, fases, atividades e pacotes de trabalho, onde as fases são: identificação e seleção da oportunidade de negócio, geração e seleção de conceito, detalhamento e seleção do conceito detalhado, desenvolvimento e análise do produto e processo, execução da produção e do plano de marketing, conclusão do PDP, registro do produto na Anvisa e lançamento do produto e avaliação pós-vendas.

Rozenfeld et al. (2006) mostram a importância das atividades de pós-desenvolvimento para melhoria do PDP, através do acompanhamento do produto no mercado e da retirada sistemática do produto. Os autores ressaltam a necessidade de integração dos fornecedores no desenvolvimento para obter agilidade e sucesso, assim como o monitoramento constante da viabilidade econômico-financeira do projeto e produto para garantir que as premissas e indicadores iniciais sejam mantidos. A estrutura do modelo é apresentada em macrofases, fases e atividades, onde as fases são: planejamento

Quadro 2. Classificação de novos produtos.

\begin{tabular}{|c|c|}
\hline Classificação & Definição \\
\hline Extensão de linha & Quando o novo produto é lançado dentro de uma linha de produtos já existentes no mercado \\
\hline Reposicionamento de produto existente & Quando um produto existente é introduzido em outro mercado com apelo para outros benefícios \\
\hline Nova fórmula de produtos existentes & Quando o produto altera sua forma física \\
\hline Reformulação de produtos existentes & Quando o produto é redesenhado visando melhoria \\
\hline Novas embalagens para produtos existentes & Quanto um produto muda a embalagem \\
\hline Produto inovador & Quando um produto é desenvolvido com base na concorrência \\
\hline Produto criativo & Produto totalmente novo no mercado \\
\hline
\end{tabular}

Fonte: adaptado de Fuller (1994). 
estratégico dos produtos, planejamento do projeto, projeto informacional, projeto conceitual, projeto detalhado, preparação da produção do produto, lançamento do produto, acompanhar produto e processo e descontinuar o produto.

Santos e Forcellini (2004) realizaram uma pesquisa comparando os processos de PDP realizados por empresas de alimentos de diferentes setores, situadas no Brasil, com os modelos teóricos de PDP encontrados na literatura. A pesquisa mostrou que as empresas possuem pouca metodologia sistematizada que conduza o PDP alimentício, principalmente referente ao processo de projeto. Segundo Nantes et al. (2006), a falta de conhecimento específico no processo de projeto ocasiona que grande parte dos desenvolvimentos de produtos são extensões de linha, onde os produtos são elaborados por um sistema universal de manufatura.

\subsection{Gerenciamento da informação no PDP}

A forma como as empresas lidam com o gerenciamento da informação influencia diretamente o desempenho do PDP. Para o sucesso da gestão do PDP, as informações que entram no processo precisam ser disponibilizadas para todos participantes do projeto. Portanto, é importante criar mecanismos para registrar, armazenar, disponibilizar, transferir e facilitar a interpretação de dados, informações e conhecimentos. 0 gerenciamento da informação, quando utiliza infraestrutura de comunicação e ferramentas que apoiam o PDP, aproxima a participação dos colaboradores e compromete a geração de documentos para registro das tomadas de decisão e procedimentos realizados. 0 gerenciamento da informação é baseado no desempenho das equipes de desenvolvimento de produtos, no líder do projeto e no mecanismo de troca de informação e aprendizado (LAIDENS, 2007).

Os grupos internos e os grupos externos são responsáveis pela entrada de informações no PDP. 0 nível de cooperação e comunicação entre os grupos define a quantidade e qualidade de informações adquiridas. Os grupos internos são compostos pelas equipes de desenvolvimento, e os grupos externos são compostos pelos clientes e fornecedores. No entanto, a sistematização do fluxo de informação é dada pelo líder do projeto, que determina o gerenciamento do projeto e, consequentemente, é responsável por promover a integração entre os grupos, definir os meios de comunicação utilizados no projeto e o tipo de abordagem de gestão de desenvolvimento (CURTY, 2005; ROZENFELD et al. 2006).
Onoyama et al. (2005), Santos e Forcellini (2005) e Curty (2005) ressaltam a importância da interação dos fornecedores no PDP como facilitadores da transferência de conhecimento e do desenvolvimento de tecnologias, que normalmente são informações críticas para o fluxo do processo. 0 envolvimento dos fornecedores facilita a redução do tempo e custos do processo, pois a troca de informações potencializa a geração de alternativas de solução, evitando erros e retrabalhos desnecessários durante o projeto.

A existência de infraestrutura de comunicação que garanta o fluxo contínuo de informação é essencial, pois em cada atividade do PDP deve-se identificar qual informação precisa estar disponível para fundamentar e conduzir a atividade. Por sua vez, as principais informações geradas durante as atividades devem ser armazenadas, formando a memória do PDP. A infraestrutura de comunicação precisa estar adequada à empresa, de maneira que o fluxo de informações não fique estagnado de tempos em tempos (CURTY, 2005; ECHEVESTE, 2003).

0 objetivo de documentar o andamento do PDP tem as seguintes funções: (i) estabelecer um mecanismo de comunicação entre as fases, apresentando os resultados da fase; (ii) armazenar as informações que auxiliam na formação do histórico dos projetos; e (iii) estabelecer um meio de comunicação durante a execução das atividades, auxiliando a equipe no controle dos aspectos críticos. Os documentos operacionalizam o trabalho das diferentes equipes que atuam no desenvolvimento, evitando reuniões desnecessárias ou afastadas do assunto principal, além de garantir que decisões sejam tomadas com o comprometimento dos envolvidos (ECHEVESTE, 2003).

As lições aprendidas durante o desenvolvimento do projeto devem ser documentadas. É importante que todos os participantes descrevam as informações que foram essenciais para a realização de suas atividades e os conhecimentos aprendidos. As lições devem ser armazenadas num banco de dados, de maneira que as novas equipes de DP tenham acesso aos registros, conduzindo à melhoria contínua do PDP (ROZENFELD et al., 2006; ECHEVESTE, 2003).

0 emprego de ferramentas de apoio ao PDP facilita a integração da equipe e a geração de documentos para registro da tomada de decisão e procedimentos realizados. Antes de implementar as ferramentas, deve-se estruturar o PDP através de modelos referenciais para, num segundo momento, localizar as ferramentas nesta estrutura e, num terceiro momento, aplicar as ferramentas para criar as bases da gestão do conhecimento no âmbito do 
PDP da empresa. As ferramentas aplicadas permitem que o indivíduo aprenda sobre o seu projeto e as experiências dos outros. Esse aprendizado pode ser usado para solucionar problemas e estimular o potencial criativo (LAIDENS, 2007; ROZENFELD et al., 2006).

\section{Diagnóstico do ambiente moageiro de trigo}

Para Zuin (2004), antes de elaborar e conduzir o plano de desenvolvimento do produto, as informações sobre as características do setor, descrição de mercado, necessidades dos clientes e estudo dos processos devem ser consideradas. 0 diagnóstico do ambiente de intervenção objetiva avaliar o setor moageiro de trigo para identificar os aspectos que influenciam o sucesso dos novos produtos.

0 histórico da indústria de trigo é marcado até a década de 50 por frequentes crises no abastecimento, pois o Brasil não apresentava nenhuma região especialmente adaptada ao trigo. No final dos anos 60, o Decreto-lei n. ${ }^{0} 210$ foi promulgado para banir as fraudes, modernizar a agricultura priorizando a comercialização de trigo nacional, alavancar o processo de industrialização e normalizar o abastecimento de trigo e derivados. Em 1990, com o aumento do déficit público, devido aos preços de venda do trigo ao moinho não serem equivalentes aos gastos do governo com a compra, armazenamento e distribuição de trigo, o Decreto-lei n. ${ }^{\circ} 210$ foi revogado e o mercado da indústria de trigo aberto (RAE, 2008; KIRSCHNER, 2003).

Conforme o estudo de Campos (2004), as principais ações implementadas pelos moageiros após a abertura do mercado foram: lançamento de novos produtos por 42,1\% das empresas, investimento em desenvolvimento tecnológico e melhoria na qualidade dos produtos ofertados por $21 \%$ das empresas, treinamento em desenvolvimento pessoal por $15,8 \%$ das empresas e investimento na melhoria do atendimento ao consumidor, colocando seus recursos na estrutura industrial e a logística de distribuição por 10,5\% das empresas. 0 lançamento de novos produtos foi alavancado pelo aumento do poder de compra da população brasileira que facilitou a conquista de novos mercados. Segundo a pesquisa desse autor, 63\% dos moinhos já estão trabalhando com pesquisa e desenvolvimento e com sistema de custeio, para ingressarem nos novos mercados.
Para Oliveira (2003), o mapeamento do mercado consumidor é importante para a empresa conhecer as características de cada segmento e concentrar o desenvolvimento do produto em mercados atrativos, aumentando as chances de sucesso do produto. Os mercados atrativos são aqueles que estão crescendo e nos quais a empresa se encontra bem posicionada, ou aqueles mal atendidos pela concorrência. 0 mercado consumidor da indústria moageira de trigo são as indústrias de panificação, biscoitos, massas, químicas, de ração animal, o segmento doméstico e ela própria, com a produção de misturas à base de farinha. A moagem do trigo gera $25 \%$ de farelo, composto por casca e gérmen do grão e $75 \%$ de farinha de trigo, composto pelo endosperma.

Conforme dados do Programa de Apoio à Panificação - Propan (2008), as farinhas produzidas no Brasil são destinadas aos seguintes mercados: 55\% ao segmento de panificação, $17 \%$ ao segmento doméstico, $15 \%$ ao segmento de massas, $11 \%$ ao segmento de biscoitos e $2 \%$ destinados à indústria química e farmacêutica. Apesar de o mercado de panificação ser o maior, o consumo médio de pão no Brasil (25 kg per capita/ano) está abaixo da porção recomendada pela Organização Mundial de Saúde (60 kg per capita/ano). 0 consumo brasileiro de derivados de trigo tem um grande potencial de expansão, porém essa expansão ocorrerá caso as empresas consigam se posicionar frente a outras culturas, através da estratégia de educação do consumidor sobre a importância da ingestão de trigo e diferenciação de produtos para responder aos desejos dos consumidores.

A estrutura organizacional da empresa define 0 modo de trabalho dos projetos. A capacidade de integração e o porte da empresa têm influência direta no tipo de estrutura organizacional. Normalmente, as empresas moageiras de médio e pequeno porte não possuem funcionários especializados para as diversas áreas da empresa. 0 funcionário agrega mais de uma função além de dividir o tempo entre o PDP e as atividades de rotina da produção. A estrutura organizacional da indústria moageira pode ser de três tipos: funcional, de projeto e matricial. Na organização funcional, os membros do projeto são funcionários especialistas, que ficam sob a responsabilidade dos gerentes funcionais, ocorrendo pouca integração no PDP. $\mathrm{Na}$ estrutura por projetos, os indivíduos reportam ao líder do projeto, apresentando mais foco e maior velocidade. Na estrutura matricial, os indivíduos estão ligados ao gerente da área funcional e ao gerente do projeto, proporcionando maior flexibilidade, o que amortece o risco da organização e dos colaboradores (ROZENFELD et al. 2006). 
0 envolvimento dos fornecedores é outro fator que interfere no PDP. A integração efetiva de fornecedores no PDP traz muitos benefícios, como redução de custos, tempo e melhoria na qualidade dos insumos e acesso à aplicação de tecnologia. No entanto, a integração efetiva só ocorre quando há superação da resistência à divisão de informações técnicas (ONOYAMA et al., 2005; SANTOS; FORCELLINE, 2005; RAGATZ; HANDFIELD; SCANNELL, 1997). 0 sucesso da integração dos fornecedores no desenvolvimento de produtos depende do relacionamento estruturado entre cliente e fornecedor e da alocação de ativos (intelectual, humano e físico).

Com o objetivo de identificar as características do envolvimento dos fornecedores no PDP do setor moageiro, foi realizada uma pesquisa com três importantes fornecedores de aditivos para o setor. Foi possível constatar que as empresas de aditivos têm grande envolvimento no PDP dos moinhos de trigo. Elas dispõem de uma estrutura interna de P\&D e planta-piloto disponíveis aos clientes. A elevada integração no desenvolvimento e a estrutura de atendimento aos clientes são necessárias devido à peculiaridade do setor, pois as empresas que atuam no setor moageiro não trabalham com a mesma variedade e mesclas de trigo, o que acarreta em aditivos específicos para cada situação e cliente. Como foi relatado na pesquisa, as indústrias moageiras são pouco abertas a inovações. Assim, muitos moinhos, principalmente os de pequeno porte, não possuem estrutura que facilite o desenvolvimento de produtos, solicitando aos fornecedores de aditivo que gerenciem 0 desenvolvimento técnico.

\section{Modelo de referência do PDP para a indústria moageira de trigo}

A construção do modelo de referência foi baseada no estudo da metodologia de DIP, na análise de modelos teóricos, no diagnóstico do ambiente moageiro de trigo e na observação das práticas desenvolvidas nas empresas. Para estrutura organizacional, recomenda-se a adição dos arranjos por projetos ou matricial com forte autoridade do líder do projeto, pois isso melhora a eficiência do PDP e proporciona maior aprendizagem sistêmica sobre o projeto.

Com base no estudo de Penso (2003), foram adotadas sete diretrizes para gerenciar o PDP: abordagem de condução do PDP, envolvimento e controle de fornecedores na gestão, forma de apresentação da estrutura operacional do PDP, fluxo de informações do PDP, ferramentas de apoio ao PDP, sistema de controle do processo e sistema de registro do conhecimento.

A abordagem de condução do PDP adotada no modelo de referência é baseada no sistema Stage Gate de Cooper (1993), visto que o PDP deve ser realizado de maneira integrada por equipes multidisciplinares. Neste modelo, as atividades do planejamento estratégico do negócio e a geração de ideias antecedem o modelo, pois, a partir da decisão da direção entre inovar ou não inovar, inicia o PDP propriamente dito. 0 projeto deve ter um líder com função de promover a integração das equipes do PDP através de reuniões presenciais, controlar o cronograma do projeto, revisar os documentos de saída das fases, solicitar recursos à direção e ligar o projeto com a direção da empresa.

Os fornecedores de matéria-prima alimentícia devem interagir ao longo do PDP, atuando intensamente nas etapas de: definição das características técnicas para o produto, estudo das alternativas de aditivos, definição e testes do produto.

A apresentação da estrutura operacional do PDP é importante para oferecer uma visão comum aos colaboradores sobre o funcionamento do PDP. A estrutura é organizada em quatro níveis: macrofases, fases, atividades e tarefas. Nesta ordem, os níveis representam um aumento gradual no detalhamento do PDP. As macrofases foram instituídas para definir as atividades que antecedem o desenvolvimento, as atividades de desenvolvimento e as atividades de acompanhamento do produto após o desenvolvimento. 0 Quadro 3 apresenta a estrutura operacional do PDP para o setor moageiro caracterizando as macrofases, fases, atividades e documentos de saída. Ao término de cada fase, as principais informações de saída são reunidas em um documento de saída que deve ser avaliado pela direção, antes do seguimento para a próxima fase.

0 modelo deve ser desenvolvido com base na integração do fluxo de informação e, assim, as tarefas podem ocorrer simultaneamente, desde que as informações de entrada não dependam de dados que ainda não foram realizados. 0 fluxo de informações trocado durante o PDP deve ser registrado e organizado numa base de dados integrada, que tem como objetivo auxiliar as equipes na execução das tarefas e tomada de decisão. 0 registro das informações de entrada e saída das fases gera o conhecimento explícito, que facilita o compartilhamento e disseminação da informação para a melhoria contínua da gestão de PDP. As ferramentas de apoio devem ser utilizadas para 
Quadro 3. Estrutura operacional do PDP: macrofases, fases, atividades e documentos de saída.

\begin{tabular}{|c|c|c|c|}
\hline Macro-fase & Fase & Atividade & Documentos de saída \\
\hline \multirow{7}{*}{ 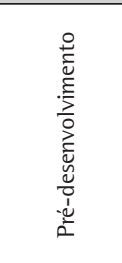 } & \multirow{2}{*}{$\begin{array}{l}\text { Planejamento do } \\
\text { portfólio de produtos }\end{array}$} & Definir banco de idéias & \multirow{2}{*}{ Minuta dos projetos } \\
\hline & & Atualizar o portfólio de produtos e priorizar projetos & \\
\hline & \multirow{4}{*}{$\begin{array}{l}\text { Planejamento } \\
\text { do projeto }\end{array}$} & Adaptar o modelo de referência, definir atividades e sequência & \multirow{4}{*}{ Plano do projeto } \\
\hline & & Definir equipe de projetos & \\
\hline & & Preparar cronograma de projetos & \\
\hline & & Analisar a viabilidade econômica do projeto & \\
\hline & \multicolumn{3}{|l|}{ Encerrar fase - Gate 1} \\
\hline \multirow{31}{*}{ 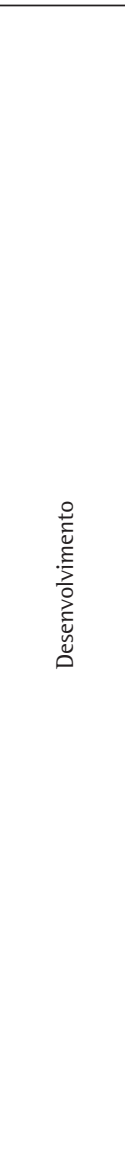 } & \multirow{5}{*}{ Projeto informacional } & ldentificar as necessidades do público alvo & \multirow{5}{*}{$\begin{array}{l}\text { Especificação-meta } \\
\text { do produto }\end{array}$} \\
\hline & & Monitorar os concorrentes no mercado & \\
\hline & & Definir as especificações e requisitos do produto & \\
\hline & & Estudar alternativas de aditivos/tecnologia & \\
\hline & & Analisar restrições de projeto & \\
\hline & \multicolumn{3}{|l|}{ Encerrar fase - Gate 2} \\
\hline & \multirow{6}{*}{ Projeto conceitual } & Gerar idéias para a concepção do produto & \multirow{6}{*}{ Plano de conceito } \\
\hline & & Desenvolver e testar alternativas de concepção do produto & \\
\hline & & Propor melhores alternativas de concepção do produto & \\
\hline & & Escolher processo de fabricação e self life & \\
\hline & & Avaliar tipos de embalagens & \\
\hline & & Monitorar viabilidade econômica & \\
\hline & \multicolumn{3}{|l|}{ Encerrar fase - Gate 3} \\
\hline & \multirow{6}{*}{ Projeto detalhado } & Escolher alternativas de produto & \multirow{6}{*}{$\begin{array}{l}\text { Plano detalhado do } \\
\text { produto e processo }\end{array}$} \\
\hline & & Projetar embalagem & \\
\hline & & Detalhar processo de fabricação, embalagem, envase e distribuição & \\
\hline & & Definir e qualificar fornecedores & \\
\hline & & Elaborar plano de qualidade para produto e processo & \\
\hline & & Planejar produção do lote & \\
\hline & \multicolumn{3}{|l|}{ Encerrar fase - Gate 4} \\
\hline & \multirow{10}{*}{$\begin{array}{l}\text { Preparação da produção e } \\
\text { lançamento do produto }\end{array}$} & Desenvolver plano de marketing do produto & \multirow{10}{*}{$\begin{array}{l}\text { Documentos de } \\
\text { liberação de produção } \\
\text { Registro do } \\
\text { conhecimento }\end{array}$} \\
\hline & & Instalar recursos & \\
\hline & & Produzir lote & \\
\hline & & Homologar produto e processo & \\
\hline & & \begin{tabular}{|l|} 
Registrar produto e processo \\
\end{tabular} & \\
\hline & & Liberar produção & \\
\hline & & Monitorar viabilidade econômica & \\
\hline & & Detalhar procedimento do serviço de atendimento ao consumidor (SAC) & \\
\hline & & Implementar estratégia de lançamento de produto & \\
\hline & & Registrar conhecimento e lições aprendidas & \\
\hline & Encerrar fase - Gate 5 & & \\
\hline \multirow{7}{*}{ 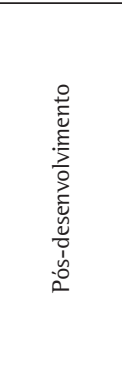 } & \multirow{3}{*}{$\begin{array}{l}\text { Acompanhamento do } \\
\text { produto e processo }\end{array}$} & Realizar auditoria no processo pós-projeto & \multirow{3}{*}{$\begin{array}{l}\text { Relatório de desem- } \\
\text { penho do produto } \\
\text { Plano de melhoria }\end{array}$} \\
\hline & & Monitorar desempenho do produto e projeto & \\
\hline & & Consolidar informações sobre desempenho & \\
\hline & \multicolumn{3}{|l|}{ Encerrar fase - Gate 6} \\
\hline & \multirow{2}{*}{$\begin{array}{l}\text { Retirada do produto } \\
\text { do mercado }\end{array}$} & Implementar plano de retirada do produto do mercado & \multirow{2}{*}{$\begin{array}{l}\text { Plano de retirada } \\
\text { do produto } \\
\text { Relatório final } \\
\text { do projeto } \\
\text { Registro do } \\
\text { conhecimento }\end{array}$} \\
\hline & & Encerrar projeto & \\
\hline & Encerrar fase - Gate 7 & & \\
\hline
\end{tabular}

Fonte: elaborada pela autora.

dar suporte à execução das atividades. Essa diretriz permite que as atividades do modelo proposto sejam apoiadas em sistemáticas que facilitam o alcance e a visualização dos resultados esperados como saída da atividade.
0 sistema de controle do processo incorpora a lógica do Stage Gate, onde os gates controlam a qualidade e o desempenho do projeto. A avaliação deve ser realizada pela direção toda vez que uma fase é concluída. Nessa avaliação se decide 
entre encerrar o projeto, solicitar uma revisão das atividades ou continuar o desenvolvimento avançando para a próxima fase. A avaliação da fase deve ser feita através de um formulário - check-list, que coordena a verificação do documento de saída da fase.

0 sistema de registro de conhecimento pode ser realizado quando o produto é lançado no mercado. 0 registro objetiva documentar as lições aprendidas durante o PDP. Esse documento deve incorporar as observações dos participantes envolvidos no PDP. Quando o produto é descontinuado, o registro é complementado com dados sobre avaliação de desempenho do produto. As lições aprendidas devem ser difundidas pela empresa facilitando novos desenvolvimentos de produtos.

\section{Aplicação do modelo proposto}

A aplicação do modelo proposto foi realizada em uma empresa moageira de médio porte, situada no Rio Grande do Sul. A adaptação do modelo de referência às características da empresa foi realizada através de um plano de sistematização do PDP, com as seguintes etapas: (i) analisar a situação atual do PDP; (ii) propor melhorias; e (iii) definir um modelo de PDP com a aplicação das melhorias.

A situação atual da empresa foi avaliada comparando o modelo proposto com a estrutura de desenvolvimento de produto que existe na empresa. Com isso, foi possível diagnosticar os pontos do
PDP a serem melhorados nas práticas de gestão e na estrutura operacional do PDP. Os pontos de melhoria para a empresa estão apresentados nos Quadros 4 e 5. Baseado na análise da situação atual da empresa foram propostas ações de melhoria para aumentar a maturidade do PDP, com execução a curto e médio prazo.

A melhoria nas práticas de gestão do PDP deve partir da elaboração de um modelo de referência exequível, que deve ser aprimorado e mais bem detalhado conforme a empresa for desenvolvendo novos projetos. 0 modelo deve possuir uma estrutura de banco de dados capaz de melhorar a gestão da informação através do armazenamento e disponibilização das informações para os colaboradores. 0 banco de dados deve conter campos para controlar as matérias-primas e fornecedores pesquisados, assim como campos para registrar as lições aprendidas pelos integrantes do PDP.

Aumentar a integração entre os departamentos e adotar gates para controlar as etapas do processo aproximam a participação dos colaboradores. A melhoria da integração pode ser realizada colocando os assuntos de desenvolvimento que precisam ser compartilhados nas pautas de reuniões da produção. A implementação dos gates após as fases aumenta o contato da direção com a equipe de projetos.

A utilização de ferramentas de apoio também facilita a integração entre os departamentos e

Quadro 4. Identificação dos pontos que podem ser melhorados nas práticas de gestão da empresa.

\begin{tabular}{|c|c|}
\hline Prática de gestão & Pontos de melhoria \\
\hline Abordagem de condução do PDP & Aumentar a integração entre os departamentos \\
\hline Envolvimento dos fornecedores na gestão & Registrar pesquisa de matéria-prima e avaliar os seus fornecedores \\
\hline Forma de apresentação da estrutura operacional do PDP & Desenvolver um modelo de estrutura com documentos de saída \\
\hline Fluxo de informação do PDP & Melhorar a infraestrutura de informação \\
\hline Ferramentas de apoio do PDP & Aumentar a utilização de ferramentas de integração \\
\hline Sistema de controle do processo & Adotar gates para controlar as etapas do processo \\
\hline Sistema de registro do conhecimento & Desenvolver a prática do registro das lições aprendidas \\
\hline
\end{tabular}

Fonte: elaborada pela autora.

Quadro 5. Identificação dos pontos que podem ser melhorados na estrutura operacional do processo.

\begin{tabular}{|c|c|}
\hline Fase do PDP & Pontos de melhoria \\
\hline $\begin{array}{c}\text { Informação de entrada para o planejamento } \\
\text { do portfólio de produtos }\end{array}$ & Estruturar o planejamento estratégico do negócio \\
\hline Planejamento do portfólio de produtos & $\begin{array}{c}\text { Estruturar o planejamento do portfólio de produtos; criar um documento de registro } \\
\text { do projeto a ser desenvolvido, incluindo informações sobre o produto }\end{array}$ \\
\hline Planejamento do projeto & Definir responsabilidades e cronograma de atividades de cada projeto \\
\hline $\begin{array}{c}\text { Planejamento do projeto, projeto conceitual, } \\
\text { lançamento do produto }\end{array}$ & Desenvolver análise da viabilidade econômica ao longo do projeto \\
\hline Retirada do produto do mercado & Definir uma sistemática para retirada do produto do mercado \\
\hline
\end{tabular}

Fonte: elaborada pela autora. 
melhora a qualidade da informação de saída. Para isso é importante capacitar a equipe comercial para desenvolver formalmente as atividades de marketing, tais como mapeamento de mercado, levantamento de oportunidades e necessidades de clientes. Paralelamente, o departamento de qualidade deve utilizar ferramentas formais, como análise paramétrica, análise morfológica e QFD, visando aumentar a socialização e externalização do conhecimento organizacional.

A estrutura operacional do PDP pode ser melhorada partindo da institucionalização do planejamento estratégico e disseminação das metas do planejamento para os integrantes da empresa. A evolução do planejamento pode ser realizada gradualmente, porém deve contemplar em qual segmento de mercado e quais linhas de produtos a empresa pretende crescer e fixar esforços. Estruturar o planejamento do portfólio de produtos é outra atividade fundamental. Em um primeiro momento, pode-se elaborar um planejamento simplificado. No futuro, o planejamento do portfólio pode ser aprimorado, acompanhando a maturidade de gestão e inovação da empresa.

A definição de responsabilidades e cronograma de atividades de cada projeto deve ser controlada com a matriz de atividades versus responsabilidades, que contenha uma coluna para previsão de término de cada atividade. Na estrutura operacional, a atividade de análise da viabilidade econômica deve acontecer com frequência maior, sendo que a atualização do custo-alvo do produto deve ser realizada em conjunto pelas áreas técnica e financeira. Outra melhoria na estrutura operacional do processo é a adição da fase de retirar o produto do mercado, partindo de fatores estabelecidos pela direção.

\subsection{Modelo para a empresa em estudo}

0 modelo de referência criado para a empresa foi baseado na integração do fluxo de informação. Um banco de dados integrado, operando em ambiente web, foi proposto para melhorar o controle do PDP e a integração entre os departamentos. 0 banco de dados permite que as informações importantes, constatadas ao longo das fases, sejam armazenadas, editadas, salvas, excluídas, consultadas e impressas. Essa é uma solução integrada, na qual: (i) todas as informações estão disponíveis no mesmo ambiente; (ii) as buscas podem ser realizadas de forma variada; e (iii) com o nome de usuário e senha, o banco de dados pode ser acessado em qualquer lugar e torna-se confiável, pois os campos ficam restritos a usuários permitidos.
0 modelo para a empresa tem a mesma estrutura de macrofases e fases do modelo de referência. No entanto, as atividades foram modificadas visando adequação à rotina e recursos da empresa, conforme Quadro 6. Quatro gates para controle foram definidos nas fases onde a direção possui menor interação com o projeto, devido à especificidade técnica das atividades.

0 banco de dados de desenvolvimento dispõe dos seguintes espaços de web: (i) ideia de produto; (ii) desenvolvimento do produto; (iii) matériaprima; (iv) embalagem; e (v) RNC. Nesses espaços, é possível inserir, editar e excluir informações em formulário web, que ficam armazenadas para posterior consulta. A estrutura permite consulta avançada, onde mais de um campo de informação pode ser delimitado. Ao final da consulta, há a possibilidade de imprimir os itens encontrados ou visualizar seus formulários, tendo o recurso de copiar ou imprimir.

No espaço de ideias de produtos, podem ser registradas todas as ideias que surgem durante 0 ano, oriundas de fontes internas ou externas. Essas ideias entram na fase de planejamento do portfólio de produtos e auxiliam a direção a definir o projeto de desenvolvimento. A busca pela ideia de produtos pode ser realizada pelos campos de sugestão de produto, responsável pela ideia, período e palavraschave. As palavras-chave são definidas usando as sete classificações de Fuller (1994).

No espaço de desenvolvimento do produto, são armazenadas as informações de saída das fases utilizando os seguintes formulários web: minuta do projeto, plano do projeto, especificação-meta do produto, plano do produto, plano do processo, lições aprendidas e plano de retirada do produto do mercado. Cada produto possui seu formulário, que possibilita verificar se as informações constantes nele passaram pelo gate de avaliação realizado pela direção e o resultado da avaliação.

$\mathrm{Na}$ fase do projeto conceitual são realizados muitos estudos de matéria-prima. Assim, é interessante que as matérias-primas sejam cadastradas no banco de dados de desenvolvimento. 0 cadastro da matériaprima engloba: (i) validade da matéria-prima; (ii) funções desempenhadas; (iii) legislações que regulam sua utilização; (iv) dosagem máxima permitida; (v) cuidados importantes ao manipular ou processar a matéria-prima; (vi) produtos para os quais ela é recomendada; (vii) formulações de produto onde ela é utilizada; (viii) principais fornecedores; e (ix) avaliação dos fornecedores. $A$ avaliação de fornecedores engloba aspectos de desempenho da matéria-prima no produto testado, 
Quadro 6. Estrutura operacional do PDP da empresa: macrofases, fases, atividades e documentos de saída.

\begin{tabular}{|c|c|c|c|}
\hline Macro-fase & Fase & Atividade & Documentos de saída \\
\hline \multirow{6}{*}{ 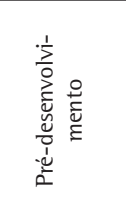 } & \multirow{2}{*}{$\begin{array}{l}\text { Planejamento do } \\
\text { portfólio de produtos }\end{array}$} & Estudar banco de ideias & \multirow{2}{*}{ Minuta dos projetos } \\
\hline & & Definir projetos & \\
\hline & \multirow{3}{*}{$\begin{array}{l}\text { Planejamento } \\
\text { do projeto }\end{array}$} & Adaptar o modelo da empresa & \multirow{3}{*}{ Plano do projeto } \\
\hline & & Preparar cronograma & \\
\hline & & Definir equipe de projeto & \\
\hline & \multicolumn{3}{|l|}{ Encerrar fase - Gate 1} \\
\hline \multirow{26}{*}{ 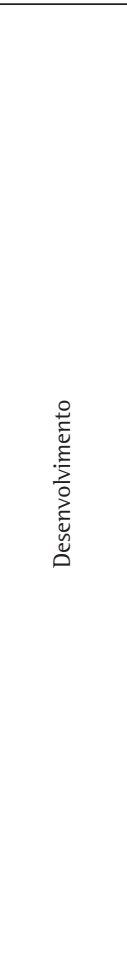 } & \multirow{4}{*}{ Projeto informacional } & Identificar as necessidades do público alvo & \multirow{4}{*}{$\begin{array}{l}\text { Especificação-meta } \\
\text { do produto }\end{array}$} \\
\hline & & Monitorar os concorrentes no mercado & \\
\hline & & Definir as especificações e requisitos do produto & \\
\hline & & Estabelecer restrições de projeto & \\
\hline & \multicolumn{3}{|l|}{ Encerrar fase - Gate 2} \\
\hline & \multirow{8}{*}{ Projeto conceitual } & Estudo de aditivos/tecnologia & \multirow{8}{*}{ Plano do produto } \\
\hline & & Gerar ideias para a concepção do produto & \\
\hline & & Desenvolver e testar alternativas de concepção do produto & \\
\hline & & Propor melhores alternativas de concepção do produto & \\
\hline & & Definir produto & \\
\hline & & Avaliar tipos de embalagens & \\
\hline & & Avaliar processo de fabricação & \\
\hline & & Monitorar viabilidade econômica & \\
\hline & \multicolumn{3}{|l|}{ Encerrar fase - Gate 3} \\
\hline & \multirow{4}{*}{ Projeto detalhado } & Projetar embalagem & \multirow{4}{*}{ Plano do processo } \\
\hline & & Detalhar processo de fabricação & \\
\hline & & Definir fornecedores & \\
\hline & & Planejar produção do lote-teste & \\
\hline & \multicolumn{3}{|l|}{ Encerrar fase - Gate 4} \\
\hline & \multirow{7}{*}{$\begin{array}{l}\text { Preparação da produção e } \\
\text { lançamento do produto }\end{array}$} & Verificar e instalar recursos & \multirow{7}{*}{$\begin{array}{l}\text { Registro das lições } \\
\text { aprendidas }\end{array}$} \\
\hline & & Produzir lote-teste & \\
\hline & & Homologar produto e processo & \\
\hline & & Registrar produto e processo & \\
\hline & & Liberar produção & \\
\hline & & Monitorar viabilidade econômica & \\
\hline & & Registrar lições aprendidas & \\
\hline \multirow{3}{*}{ 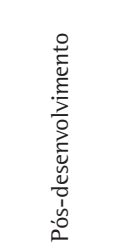 } & $\begin{array}{l}\text { Acompanhamento do } \\
\text { produto e processo }\end{array}$ & Monitorar desempenho do produto e projeto & $\begin{array}{l}\text { Relatório de não } \\
\text { conformidade do } \\
\text { produto }\end{array}$ \\
\hline & \multirow{2}{*}{$\begin{array}{l}\text { Retirada do produto } \\
\text { do mercado }\end{array}$} & Avaliar retirada do produto & \multirow{2}{*}{$\begin{array}{l}\text { Plano de retirada } \\
\text { do produto }\end{array}$} \\
\hline & & Implementar plano de retirada do produto do mercado & \\
\hline
\end{tabular}

Fonte: elaborada pela autora.

prazo de entrega e segurança no fornecedor (qualidade). 0 armazenamento das informações detalhadas sobre matérias-primas facilita os próximos desenvolvimentos e auxilia na gestão de fornecedores. Apoiado nas informações disponíveis é possivel identificar para quais matérias-primas é preciso desenvolver fornecedores.

$\mathrm{Na}$ fase do projeto detalhado, identificou-se a possibilidade de incluir no banco de dados as informações sobre as embalagens dos produtos. Os dados cadastrados incluem: produto para qual a embalagem foi projetada, material utilizado, gramatura, dimensão, cor pantone, ilustração da arte, dimensão da arte, ingredientes do produto, tabela nutricional, código de barras, peso do produto e observações pertinentes aos dizeres obrigatórios pela legislação. A forma de procura por embalagem pode ser realizada pelos campos: produto, material utilizado, gramatura, código de barras e peso do produto. A inserção do cadastro de embalagens no banco de dados facilita: (i) envio das informações técnicas para novo fornecedor de embalagem; (ii) controle de criação e alterações em embalagens; (iii) disseminação de mudanças na embalagem; e (iv) a inspeção de amostras em um novo fornecimento de embalagens. 
Uma maneira de acompanhar o produto após o lançamento é o registro de não conformidades (RNC) levantadas por clientes internos e externos, através do formulário de RNC. Cada unidade moageira pode cadastrar as RNC neste espaço. 0 registro de RNCs em um ambiente integrado facilita o acompanhamento do produto desenvolvido. As soluções para as não conformidades cadastradas pelos técnicos também ficam disponíveis no mesmo ambiente. A busca das não conformidades pode ser realizada através de cliente, tipo de não conformidade, período, unidade moageira e produto. As consultas permitem visualizar: (i) o número de reclamações associadas a cada produto; (ii) as maiores reclamações encontradas; (iii) os clientes que mais reclamam; (iv) as unidades que tiveram reclamações; e (v) as soluções encaminhadas para cada reclamação. 0 sistema permite monitorar o desempenho dos produtos. No futuro, essas informações podem subsidiar o planejamento estratégico e a política de investimentos.

0 modelo desenvolvido promove interação entre as áreas funcionais, valoriza o conhecimento heterogêneo e amplia a participação de fornecedores e clientes. Dessa forma, a utilização do sistema web, apoiado em um banco de dados integrado, propicia a gestão do conhecimento no âmbito do PDP, registrando e disseminando ideias, projetos, informações técnicas, reclamações e soluções. 0 resultado é maior agilidade nas diversas etapas do PDP, devido à base sólida para o encaminhamento de novos projetos.

\section{Conclusões}

Este artigo apresentou um modelo de referência para o PDP do setor moageiro de trigo, firmado na abordagem de desenvolvimento integrado do produto. 0 referencial teórico foi embasado em duas fontes de pesquisa: as melhores práticas de gestão e modelos de referência para o PDP que abortam a estrutura operacional do PDP. Dentre os modelos pesquisados na literatura, não foi identificado um modelo específico para o setor em estudo. A composição do modelo para a indústria moageira de trigo teve como referência os modelos de Rozenfeld et al. (2006), Paula (2004) e Penso (2003), que apresentam aspectos importantes para o sucesso dos projetos, tais como integração do desenvolvimento, onde as atividades podem ser desempenhas em paralelo, utilização de ferramentas para promover o fluxo de informação e participação dos fornecedores.

0 modelo proposto é estruturado nas macrofases pré-desenvolvimento, desenvolvimento e pós-desenvolvimento. 0 pré-desenvolvimento possui as fases de planejamento de portfólio de produtos e planejamento de projetos. 0 desenvolvimento tem as fases de projeto informacional, projeto conceitual, projeto detalhado e preparação de produção e lançamento do produto. 0 pós-desenvolvimento possui as fases de acompanhamento do produto e processo e retirada do produto do mercado. Em cada atividade que compõem as fases há entradas e saídas de informações. Ao final de cada fase é desenvolvido um documento com uma síntese dos resultados obtidos, que deve ser aprovado pela direção.

A aplicação envolveu a sistematização do PDP de uma empresa do setor moageiro, com ênfase nas práticas que devem ser utilizadas para gestão e estruturação operacional do PDP. 0 método de intervenção utilizado para sistematizar o PDP possui as etapas: (i) analisar a situação atual do PDP, (ii) propor melhorias e (iii) implantar o modelo de PDP com a aplicação das melhorias. A principal contribuição do modelo junto à empresa foi a proposta de integração do fluxo de informação, através de um banco de dados integrado desenvolvido em ambiente web. 0 banco de dados proporciona que as informações importantes gerem o crescimento do conhecimento e o amadurecimento da estrutura organizacional.

\section{Referências}

CAMPOS, L. F. R. O desempenho competitivo do setor moageiro do trigo no Brasil no período pós 1990. 2004. 198 f. Tese (Doutorado em Engenharia de Produção)Universidade Federal de Santa Catarina, Florianópolis, 2004.

CLARK, K. B.; WHEELWRIGHT, S. C. The product development challenge: Competing through speed, quality, and creativity. Boston: Harvard Business Press, 1994. 431 p.

CLARK, K. B.; FUJIMOTO, T. Product development performance: Strategy, organization and management in the world auto industry. Boston: Harvard Business School Press, 1991. 409 p.

COOPER, R.G. New Products: The factor that drives success. International Marketing Review, v. 11, n. 1, p. 60-76, 1994. http://dx.doi.org/10.1108/02651339410057527

COOPER, R.G. Winning at new products. Accelerating the process from ldea to Launch. 2. ed. Massachutsetts: Perseus Books, 1993.

COOPER, R.G.; KLEINSCHMIDT, E. J. An investigation into the new product process: steps, deficiencies, and impact. Journal of Product Innovation Management, v. 3, p. 71-85, 1986. http://dx.doi.org/10.1016/07376782(86)90030-5

CURTY, R. G. O fluxo da informação tecnológica no projeto de produtos em indústrias de alimentos. 2005. $247 \mathrm{f}$. Dissertação (Mestrado em Ciência da Informação)-Centro de Ciências da Educação, Universidade Federal de Santa Catarina, Florianópolis, 2005. 
ECHEVESTE, M. E. S. Uma abordagem para estruturação e controle de processo de desenvolvimento de produtos. 2003. 224 f. Tese (Doutorado em Engenharia de Produção)-Escola de Engenharia, Universidade Federal do Rio Grande do Sul, Porto Alegre, 2003.

FULLER G. W. New food product development: From concept to marketplace. Boca Raton: CRC Press, 1994. 275 p.

KIRSCHNER, A. M. J. Macêdo: Grande grupo moageiro brasileiro - Estratégias durante a regulamentação estatal e na pós-deregulamentação. In: CONGRESSO BRASILEIRO DE HISTÓRIA ECONÔMICA, 5., 2003; CONFERÊNCIA INTERNACIONAL DE HISTÓRIA DE EMPRESAS, 6., 2003, Caxambu. Anais... Caxambu: ABPHE, 2003.

LAIDENS, G. Modelo conceitual de integração de ferramentas no processo de desenvolvimento de produtos alimentícios utilizando os princípios da gestão do conhecimento. 2007. 132 f. Dissertação (Mestrado em Engenharia de Produção)-Escola de Engenharia, Universidade Federal do Rio Grande do Sul, Porto Alegre, 2007.

MANO, A. P.; TOLEDO, J. C. A integração interfuncional na gestão de desenvolvimento do produto: um estudo de caso em uma empresa de máquina agrícola. In: CONGRESSO BRASILEIRO DE GESTÃO DO DESENVOLVIMENTO DE PRODUTOS, 5., 2005, Curitiba. Anais... Curitiba: CEFET, 2005. CD-ROM.

NANTES, J. F. D.; ABREU, A.; LUCENTE, A. R. The role of technological innovation in the development of new products: a study in the food industries. Product: Management \& Development, v. 4, n. 1, 2006.

OLIVEIRA, C. A. Inovação da tecnologia, do produto e do processo. Belo Horizonte: Editora de Desenvolvimento Gerencial, 2003. 311 p.

ONOYAMA, M. M. et al. Involvement of ingredients suppliers in new products development in the soft drinks industry. Product: Management \& Development, v. 3, n. 1, p. 55-60, 2005.

PAULA, l. C. Proposta de um modelo de referência para o processo de desenvolvimento de produtos farmacêuticos. 2004. 316 f. Tese (Doutorado em Engenharia de Produção)-Escola de Engenharia, Universidade Federal do Rio Grande do Sul, Porto Alegre, 2004.
PENSO, C. C. Modelo de referência para o processo de desenvolvimento de produtos na indústria de alimentos. 2003. 182 f. Dissertação (Mestre em Engenharia Mecânica)-Engenharia Mecânica, Universidade Federal de Santa Catarina, Florianópolis, 2003.

PINOTT, S. E. Proposta de implantação de um modelo de desenvolvimento de produtos no setor de modelagem em uma empresa de calçados. 2003. 195 f. Dissertação (Mestrado Profissionalizante em Engenharia de Produção)-Escola de Engenharia, Universidade Federal do Rio Grande do Sul, Porto Alegre, 2003.

PROGRAMA DE DESENVOLVIMENTO DA ALIMENTAÇÃO, CONFEITARIA E PANFIICAÇÃO - PROPAN. Site Institucional. Disponível em: <http://www.propan.com. br/>. Acesso em: 18 mai. 2008.

RAE, R. P. O papel do trigo na evolução da humanidade: a triticultura brasileira. Disponivel em: <http://www. abitrigo.com.br>. Acessado em: 3 jun. 2008.

RAGATZ, G. L.; HANDFIELD, R. B.; SCANNELL T. V. Success factors for integrating suppliers into new product development. Journal of Product Innovation Management, v. 14, p. 190-202, 1997.

ROZENFELD, $\mathrm{H}$. et al. Gestão de desenvolvimento de produtos: uma referência para melhoria de processo. São Paulo: Saraiva, 2006. 542 p.

RUDDER, A.; AINSWORTH, P.; HOLGATE D. Case study New food product development: strategies for success? British Food Journal, v. 103, n. 9, p. 657-670, 2001. http://dx.doi.org/10.1108/00070700110407012

SANTOS, A. C.; FORCELliNI, F. A. Assessment of supplier involvement in the product development process (PDP) based on a reference model for the food industry. Product: Management \& Development, v. 3, n. 1, p. 49-54, 2005.

SANTOS, A. C.; FORCELLINI, F. A. 0 processo de desenvolvimento de produtos em empresas de alimentos. In: ENCONTRO NACIONAL DE ENGENHARIA DE PRODUÇÃO, 24., 2004, Florianópolis. Anais... Florianópolis: ABEPRO UFSC, 2004. CP-ROM.

ZUIN, L. F. S. Utilização do processo de desenvolvimento do produto na criação de um modelo para gestão da inovação na produção agropecuária - GIPA. Revista Informe Gepec, v. 8, n. 2, p. 1-15, 2004.

\title{
A reference model for the products development process for companies in the sector of milling wheat
}

\begin{abstract}
This paper presents a reference model for the milling wheat product development process (PDP). The model targets to facilitate the project of new products, evaluating necessities, requirements and limitations. It contributes to integrate and create communication among the functional areas, reducing development times. The operational structure of the model is composed of three macro-phases and eight phases. At the end of each phase, the main information is compiled in document type-form, which must pass by a top management evaluation gate. The application of the reference model was tested from a plan to systematize the PDP of a company. The intervention to adjust the reference model to the company analyzes the actual PDP status, proposition of improvements, and the conduction of such application. Among the results, the facility to apply the proposed solutions to improve the company's PDP using the reference model stand out, showing the practical adequacy of the proposed model.
\end{abstract}

\section{Keywords}

Product development process. Milling wheat sector. Reference model. 